Wanderley Guilherme dos Santos *

\title{
Explicação e Predição de Desenvolvimento Político: \\ Um Exercício em Construção Teórica
}

Neste trabalho trataremos de padrões de explicação e predição próprios da literatura sôbre desenvolvimento político e discutiremos problemas de estratégia de construção teórica. 0 pressuposto mais geral consiste no fato de que o conceito de desenvolvimento político introduz não apenas um nôvo têrmo no vocabulário da Ciência Política, mas consiste também em uma forma útil de nos referirmos a um conjunto diferenciado de fenômenos. Dito de outra forma, supõe-se que o conceito de desenvolvimento político aumenta a taxa de informação muito mais que a taxa de redundância na nomenclatura da Ciência Política. ${ }^{1}$ Existem, no entanto, outros pressupostos que exigem uma definição explícita no início da discussão. Nesta seção introdutória definiremos tais pressupostos a fim de tornar mais precisa a preocupação fundamental do trabalho.

Em primeiro lugar, convém salientar que estamos lidando com uma amostra da literatura sôbre desenvolvimento político e não pretendemos efetuar uma revisão completa. A razão para assim procedermos assume um caráter essencialmente prático, uma vez que é inviável cobrir tôda a literatura mais ou menos relacionada ao tópico. ${ }^{2}$ Outra razão, e esta de caráter mais teórico, tem a ver com o fato de que com a ausência de uma teoria sôbre o desenvolvimento político mais amplamente aceita, torna-se difícil distinguir estudos que tenham ou não contribuído para a sua formulação. Na ausência de tal teoria, não podemos dizer que tipo de estudos mais se relacionam com o tema. A \footnotetext{
* Diretor de Estudos Pós-Graduados do instituto Universitário de Pesquisas do Rio de Janeiro.

1 A respeito do surgimento de vocábulos, sem o acrescimo correspondente de informaçåo, cf. Verba, Sydney, Comparative political culture. Pye, Lucien \& Verba, Sydney (eds.) Political culture and political development. p. $514-15$, e ainda Pye, Lucien, Aspects of political development. p. 31

- Cf. Pye Lucien. op. cit. ps. 31-39. Packenham, Robert. The study of political development. Stanford University, mimeo.,
} agô. 1967. 
solução consistiu em tomar uma revisão reconhecidamente aceitável como base para a discussão. ${ }^{3}$

Convém então qualificarmos os objetivos do nosso trabalho, a fim de incluirmos tal restrição. O trabalho trata assim dos padrões típicos de explicação e predição, tais como aparecem nas admitidas contribuições para a teoria do desenvolvimento político.

Em segundo lugar, o trabalho pretende ficar no nivel mais abstrato de análise e inclui apenas aquêles aspectos da literatura referentes a problemas de explicação e predição do desenvolvimento político. Conseqüentemente, não se procederá a uma análise exaustiva da literatura, ou seja, o trabalho refere-se apenas a tópicos selecionados, sem que se faça qualquer avaliação de sua contribuição para 0 desenvolvimento de campos específicos dentro da disciplina. ${ }^{4}$

Se desenvolvimento político fôr compreendido como um tipo especial de mudança, segue-se necessàriamente que explicá-lo significa estabelecer as causas de tal mudança, e predizer o desenvolvimento político significa indicar a direção da mudança. Qualquer elaboração teórica sôbre o desenvolvimento político inclui, portanto, a explicação da mudança política em uma direção determinada. ${ }^{5}$ Embora formais, tais qualificações já bastam para classificar um primeiro conjunto de estudos sôbre

desenvolvimento político, na medida em que abordam o tópico mais com o propósito de definir atributos cruciais típicos das comunidades políticas (polities) desenvolvidas, do que determinar os processos que conduzem a êsse estado. Essa peculiaridade, já assinalada por Diamant ${ }^{6}$ e Huntington, ${ }^{7}$ caracteriza muitos dos trabalhos classificados por Pye como estudos sôbre desenvolvimento político. ${ }^{8} 0$ problema lógico de tais estudos é que êles parecem confundir a explicação do processo de desenvolvimento com a definição do estado de desenvolvimento. Após definir o estágio final do desenvolvimento não é difícil estabelecer em que consiste o processo que a êle conduz; torna-se, assim, um simples problema de conversão tautológica. Por exemplo, se se considera como desenvolvida uma polity onde exista uma maior distribuição e reciprocidade de poder, então "mudanças no sentido de maior distribuição e reciprocidade do poder caracterizarão o desenvolvimento político. ${ }^{\theta}$ Não há nada errado aqui, porém, não há também nada certo, na medida em que o problema teórico do desenvolvimento consiste exatamente em definir as tais "mudanças em direção de".

Em muitos dêsses estudos, embora contendo alguns indicadores de como o sistema político atinge o estado de ser desenvolvido, a ênfase é dada ainda na descrição do estado final do sistema. Como exemplo desta abordagem, pode ser tomado o trabalho Burocracia e desenvolvimento político, de Eisenstadt. ${ }^{10}$ Após haver definido desenvolvimento político como "a habilidade de absorver tipos de demandas políticas e organizações variadas e em mudanças constantes" 11 êle prossegue discutindo as implicações analíticas dessa definição, apresentando apenas a seguinte observação para explicar os processos que conduziram àquela habilidade: "Tais transformações estão vinculadas ao desenvolvimento contínuo de grande fluidez do apoio politico". 12

Outra variante do mesmo padrão de teorização é o próprio Huntington, que define desenvolvimento político como o processo de institucionalização política. ${ }^{13}$ Após êste sugestivo coméço, entretanto, o grosso de seu trabalho é devotado à apresentação de indicadores que medem diferentes estados (ou estágios) de institucionalização. ${ }^{14}$ Quanto aos processos que produzem tal institucionalização, a explicação de Huntington circunscreve-se às duas sugestōes seguintes: (a) redução do ritmo de mobilização social e, (b) criação de instituições políticas fortes. ${ }^{15}$ A segunda sugestão não é muito informativa. Dizer que o processo de institucionalização política é produzido pela criaçăo de instituições políticas fortes reduz-se a um tipo de raciocínio circular. A primeira sugestão possui algum poder explicativo, embora conflite com um de seus indicadores de institucionalização, qual seja, a adaptabilidade de uma instituição. De fato, a adaptabilidade de uma instituição é função do número de desafios que ela logra ultrapassar. "Quanto mais

\footnotetext{
- Ver Riggs, Fred. The theory of political development. In: James C. Charlesworth (ed.) Contemporary political analysis.

- Esta qualíicação é feita a fim de evitarmos a controvérsia de que as críticas eventuais nảo consideram o papel, ora pioneiro, ora crítico, desempenhado por tais estudos.

s Cf., por exemplo, Almond, Gabriel. Political systems and political change. The American Behavioral Scientist, 6 (10):
6 , jun. 1963.

- Cf. Diamant, Alfred. Political development: approaches to theory and strategy. Approaches to development politics, administration, and Change. John D. Montromerv e William J. Siffin (eds.), 1966. p. 24.

7 Cf. Huntington, Samuel. Political development and Fo!itical decay. World Politics, 17 (3): 391, abr. 1965.

B Pye, Lucien. op. cit. p. 31-49.

- Frey, Frederick. Political development, power and communications in Turkey. and political development. p. 301 .

$10 \mathrm{Cf}$. Eisenstadt, S. Bureaucracy and political development. Joseph LaPalombara, (ed.) 1963.

11 Eisenstadt, S. op. cit., p. 96.

12 Eisenstadt, S. op. cit., p. 99 e segs. Esta análise está vinculada aos rroblemas discutidos também em Breakdowns of modernizations. Economic Development and Cultural Change, 12 (14): jul.. 1964.

1s Huntington, Samuel. op. cit., p. 393.

11 Huntington, Samuel. op. cit., p. 394. Deve ser dito, entretanto, que Huntington parece evitar a cossibilidade de fazer julgamentos referentes ao processo de desenvo'vimento antes que os niveis de institucionalização tenham sido descritos. Cf. op. cit., p. 405.

to Huntington, Samuel. op. cit., p. 418-19.
} 
desafios surgirem em seu ambiente e quanto mais antiga, mais adaptável será". ${ }^{10}$

Uma das fontes contemporâneas de maiores desafios para qualquer instituição política é o processo cumulativo que Deutsch caracterizou como "mobilização social", 17 e se se evita que a instituição (se é capaz) encare tais desafios, torna-se difícil verificar como ela desenvolverá sua adaptabilidade. 0 mesmo se aplica à característica de complexidade. Se "o mais simples dos sistemas políticos é aquêle que depende de um só indivíduo, 18 o processo de mobilização social pode perfeitamente implicar, pelo menos para alguns sistemas políticos, na possibilidade de se tornar mais complexo; desde que a forma alternativa de explicar a institucionalização - instituições políticas fortes implique em raciocínio circular, parece viável concluir que o processo que Huntington sugere para produzir a institucionalização possui, contraditòriamente, a propriedade de ameaçar parcialmente 0 estado de institucionalização.

Do ponto de vista da predição, porém, tanto as elaborações de Hungtington como as de Eisenstadt, bem como outras elaborações semelhantes, que sejam mais do que tautologias, oferecem algumas hipóteses interessantes a respeito do estado do sistema político. Tomemos as sugestões de Huntington referentes à redução da marcha da mobilização social.

Ao invés de tomá-las como explicativas do processo de institucionalização, vamos reapresentá-las - já que Huntington inclui a estabilidade na definição do estado do sistema político - como predição sôbre sistemas políticos desenvolvidos. A hipótese resultante seria a seguinte: quanto maior fôr a complexidade social, mais baixo o nível de comunicação, e menor o conflito interelite, tanto maior será a estabilidade política. E verdade que $\circ$ que Huntington inclui na categoria comunicação é uma combinação muito complicada de comunicação em sentido restrito, educação superior, liberdades políticas, e ritmo de desenvolvimento econômico, o que torna muito difícil a obtenção de uma medida única para tal índice. De qualquer forma, sua formulação, assim redefinida, implica em algumas condições para a estabilidade dos sistemas políticos que serão novamente mencionadas neste trabalho.

A segunda grande categoria de estudos sôbre desenvolvimento político consiste nos estudos de área. 0 que se entende por desenvolvimento, em tais estudos, é bastante claro na seguinte citação de Coleman (Nigeria, background to nationalism):

"O objetivo dêste capítulo final é oferecer um breve apanhado do desenvolvimento político durante o período 1952-1957, bem como uma análise de três aspectos especiais dêste desenvolvimento: o caráter da nova elite política que emergiu das várias eleições realizadas no período; o aparecimento formal do estado e dos movimentos minoritários à medida que a Nigéria se aproximava de sua independência; e o impulso para o estabelecimento de uma data para o autogovêrno." 19

É claro que o que se entende por desenvolvimento político, nesse contexto, são os eventos políticos que ocorreram no período estabelecido, isto é, a sucessão de marchas e contra-marchas que produziram o que em outro contexto costuma ser chamado de história política. ${ }^{20}$ Dada esta referência cronológica e especialmente restrita para o conceito, o caminho teórico seguido na elaboração é quase que mecânicamente determinado. Observa-se que a equação do desenvolvimento político é solucionada quando se encontra um processo básico que dê o racional da sucessão. Esse padrão de explicação é claramente inferido da seguinte citação:

"De fato, a natureza da subdivisão interna dentro da elite esclarecida oferece uma chave valiosa para a compreensão da história moderna da Turquia.

A inter-relação dêstes três elementos, educacionalmente distintos, fornece o tema mais simples em cujos têrmos - moderno desenvolvimento político da Turquia pode ser organizado e compreendido.

Atualmente, o Irã está em transição, e seu sistema político pode ser descrito como um sistema tradicional-racional, cujo paralelo histórico pode ser encontrado nos antigos estados monárquicos na Europa Ocidental. 0 'racional' para a tendência dinâmica em direção da racionalização pode ser encontrado na confluência da história, da personalidade e nas exigências políticas." ${ }^{21}$

Este padrão de explicação, comum à maioria dos estudos de área, pode ser compreendido como uma resposta à seguinte questão: dado o estado atual do sistema político analisado, que processos a êle conduziram? As respostas serão do tipo abaixo:

a) "Um processo de transferência institucional que produz uma tensão em subseqüência à

10 Huntington, Samuel. op. cit., p. 394. 37 Deutsch, Karl. Social mobilization and political development. In: The American Political Science Review, 15 (3): set. 1961.

Is Huntington, Samuel. op. cit., p. 399.

19 Coleman, James 5 . Nigeria, hackground to nationalism. 1968. p. 369 . O mesmo sentido contextual pode ser deduzido da utilizaçăo do conceito as páginas 4 a, apendice, p. 419.

20 Cf. Coleman, J. S. op. cit., Preface. p. 7: "This book claims to be no more than an introduction to selected aspects on the po'itical history of modern

Nigeria." Ver, ainda, p. 54.

a1 As duas primeiras citaçōes são de Frey, Frederick. The turkish elite, 1965, D. 31-9, respectivamente. A Cltima e de Binder, a changing society. 1964. p. 87 .. 
adaptação substantiva de valôres tribais a valôres seculares". ${ }^{22}$

b) Conflito entre dois sistemas de autoridade e dois conjuntos de valôres. ${ }^{23}$

c) Limitações na capacidade governamental de coação em um momento em que sua capacidade de persuasão é mínima. ${ }^{24}$

d) Conflito interelite (administradores versus produtores de solidariedade). ${ }^{25}$

e) Conflito interelite, por razões históricas, etnológicas, econômicas e culturais. ${ }^{28}$

f) "As fontes de instabilidade do sistema político iraniano são aquêles aspectos dinâmicos que tendem a reduzir a eficácia das técnicas políticas tradicionais e a alterar o padrão de legitimação tradicional." $2 z$

g) Falta de congruência entre os três processos de socialização (familístico, cultura política, e recrutamento político) e a divisão entre uma elite distinta e uma massa agrária comunitàriamente orientada, e o conflito entre administradores e políticos populares. ${ }^{28}$

h) Conflito entre a elite educada ("modernistas" versus intelectuais) e entre a elite nacional e os políticos locais. ${ }^{28}$

i) Tensões derivadas de demandas populares crescentes em fase de recursos escassos. ${ }^{30}$

Tais explicações seguem a mesma linha de demonstração. ${ }^{31}$ Riggs já salientou que tais estudos de área se baseiam bastante na visão e metodologia de outras ciências sociais. ${ }^{32}$ Mais do que isso, entretanto, manipulam grande quantidade de evidências heterogêneas - do etnológico ao psicológico, do econômico ao cultural - a fim de estabelecer a legitimidade do racional proposto. 0 tratamento dado a êsse material, porém, é pouco sistemático, sendo que a evidência é apresentada muito mais como ilustração do que como prova. ${ }^{33} \mathrm{~A}$ única exceção a êsse cânone é a obra de Frey, em que cada elaboração teórica é seguida de uma discussão das condições sob as quais a elaboração se legitima, e ainda pela apresentação e tratamento sistemático das evidências pertinentes.

Qual é o poder explicativo e preditivo dêsse tipo de estudos? Existe uma posição de certa forma inversa à da categoria precedente. Seu poder preditivo é pràticamente nulo, não apenas em relação ao que pode ocorrer em outro país, mas também em relação às perspectivas do país em questão. Não há base lógica, e nem a evidência é reunida de forma tal a permitir qualquer prognóstico. Trata-se de reconstruções ex post facto de processos singulares, e isto é o suficiente para impedir até mesmo qualquer especulação sôbre tendências. ${ }^{34}$ $\mathrm{O}$ que poderia ser dito em relação a eventos futuros, a partir do conhecimento de que aparentemente alguns eventos passados singulares podem ser referidos a outros eventos particulares?

Eles possuem, entretanto, algum poder explicativo, embora com baixo nivel de generalidade. De forma mais ou menos integrada todos êles obtêm sucesso ao mostrar uma cadeia de eventos, onde cada evento particular pode ser explicado através da referência a um outro evento em momento prévio. A sustentação lógica da ligação é a contigüidade de tempo responsável pelo baixo nível de generalidade. Mas, embora tais explicações sejam primitivas, suas base lógica é suficiente para chamar a atenção para certas conexões promissoras, que podem vir a ser bastante significativas. Coloca-se assim, o problema de como aperfeiçoar tal tipo de elaboração.

E evidente que aqui não há condição de falsificação das hipóteses. Enquanto a base ló- gica da explicação fôr a contigüidade de tempo de dois eventos, a única forma de prová-la falsa consistiria em

22 Apter, David, Ghana in transition, Atheneum ed. p. 9. Nesta e nas referéncias precedentes, estamos indicando apenas aquelas passagens em que a resposta pode ser encontrada de forma explícita. Isto não implica, portanto, que tais respostas não possam ser encontradas de forma implícita ao longo das obras.

28 Apter, David. The political kingdom in Uganda. 1961. p. 105.

24 Von Vorys. Karl, Political development in Pakistan. 1965. p. 68-9.

2s Feith. Herbert. The decline of Constitutional democracy in Indonesia. 1962. p. 608 .

* Coleman, J. S. op. cit., passim.

27 Binder, Leonard. op. cit., p. 346.

28 Pye, Lucien. Politics, personality and nation building - Burma's search for identity. parte 1, 1962. p. 64 e 98 .

Frey, Fuderick op. cit. p. 37, 38 e 157.

\$ Weiner, Myron. The politics of scarcity. 1962. passim. Certamente, a obra de Weiner não pretende ser um estudo sôbre desenvolvimento político. o mesmo ocorre com a de Coleman, cujo indice não

enfatiza o conceito: o mesmo é válido para a obra de Apter, Ghana in Transition, e para Feith. Ver a citaçáo de Coleman Feith: "Este livro trata da polftica da Feith: "Este livro trata da polftica da março de 1957 (...). Meu objetivo é, aqui, contar a história de sua tentativa, apresentando-a sob o prisma da evolução mensal dos acontecimentos do desenvolvimento da política nacional." Feith, op. cit. Prefácio.

21. Deve-se salientar que a apresentaçăo de tais livros lida apenas com os padröes Iógicos de explicação que êles desenvolvem sem considerar qualquer outra contribuiçåo que tenham prestado à ciência política.

32 Riggs, Fud. op. cit. p. 322.

* Esta rigorosa avaliação parece-nos justificada enquanto tais estudos sejam tidos como elaborações sôbre o

desenvolvimento político, o que nem

sempre é o caso. E, também, verdade que

alguns entre êles são mais rigosamente

apresentados sendo, portanto, anulados na

avaliação. No entanto, quanto a lógica

da explicaça, nenhum deles mostra um padrăo rigoroso de demonstraçăo, em padráo rigoroso de demonstraçá, virtude talvez do baixo nivel de demonstração prevalecente na ciência
política quando foram produzjdos.

* Esta proposição não quer

necessàriamente dizer que nenhum dos

autores tenha feito especulações quanto

a tendências; alguns dêles o fizeram.

Porém, tais estimativas năo foram baseadas

na estrutura da explicação apresentada

em seu trabalho. De certa forma, tais

estimativas poderiam ser feitas sem evidência apresentada, já que não é adequada à estrutura de prediçăo envolvida nas especulações de tendéncias. A categoria seguinte de estudos a ser analisada constitui-se de trabalhos mais orientados para a predição do que para a explicacáo; suas estruturas lógicas serão discutidas a seguir. Para uma avaliacão das dificuldades implícitas nas predições supostamente baseadas em tais estudos compare o "desenvolvimento político" de Gana, desde a edição do livro de Apter com os vários prefácios escritos a fim de reajustar sua opinião face aos novos acontecimentos. especialmente, o final otimista escrito em 1963, para a edição Atheneum, com o que aconteceu em Gana deste então. 
mostrar que os eventos tomados como precedentes, de fato não o são; êrro êste que não é razoável esperar. Mostrar ainda a existência de um outro evento, cuja presença sempre antecede cada acontecimento importante, também, não serviria, pois essa conexão não cancela a conexão definida como crucial na hipótese anterior. De forma mais concreta diríamos: estabelecer que antes de todos os grandes acontecimentos políticos da história da Indonésia, durante o mesmo período escolhido por Feith, houve um atrito entre parte da elite política e a elite militar não faz desaparecer o conflito dentro da elite política, definido pelo autor. E uma vez que a base lógica dessa conexão seria a mesma que a de Feith, não se poderia afirmar que uma é correta e a outra é falsa. Não obstante, algo importante teria surgido, a saber: a existência de outra explicação significativa plausível.

A possibilidade de fazer conexões na base lógica da seqüência temporal é, naturalmente, infinita. A fim de evitar as muitas pistas enganadoras - não importantes - a que êste nivel de explicação se arrisca, torna-se necessário o tratamento sistemático da evidência. A rigorosa análise empreendida por Frey não faz de sua variável básica - 0 o conflito interelite - a verdadeira explicação da história política da Turquia, já que valôres-verdade estão fora do objetivo de seu padrão de explicação. Isto, porém, torna sua explicação mais relevante do que, digamos, a elaboração de Apter sôbre a política de Gana. A replicação dêsses estudos, inclusive de Frey, com o tratamento sistemático da evidência a fim de se chegar a conexões confiáveis, limitadas pelo tempo-espaço, parece-nos ser o próximo passo estratégico nesse tipo de atividade teórica.

$\mathrm{Na}$ medida em que tais replicações rigorosas sejam feitas, algumas indicações convergentes e significativas ganharão, fôrça, apoiando elaborações mais abstratas. De fato, tais estudos tomados separadamente não levarão a parte alguma, porém avaliados como um conjunto apontam para conexões comuns. Abaixo citamos as mais evidentes: ${ }^{35}$

a) conflito ou consenso dentro da elite política, e estabilidade ou instabilidade política: Feith, Coleman, Pye e Frey;

b) pressões da estrutura societal sôbre o comportamento da elite política: Von Vorys, Pye e Weiner;

c) impacto diferencial da ação governamental devido a condições societais heterogêneas: Apter, Binder e Coleman.

0 que se identifica em tôdas essas indicações, como pode ser visto, é que o "desenvolvimento político" dêsses países é o resultado de uma combinação ainda não conhecida de recursos políticos, orientação da elite, e estrutura societal. E, pelo menos os dois últimos componentes receberão argumentos de apoio conquistados por outros.

Existe outra categoria de estudos sôbre desenvolvimento político cuja estrutura básica chamaremos de "prognóstico". Nos estudos de prognóstico, a ênfase situa-se na predição do estado do sistema político no tempo $t_{2}$ a partir de um conjunto conhecido de condições em $t_{1}$, invocando-se no entanto, não o funcionamento de uma lei geral, mas sim a propensão, ou tendências existentes dentro dos sistemas políticos. ${ }^{36}$ Um exemplo clássico dêsse tipo de elaboração é a obra de Shills, Desenvolvimento político nos novos estados, onde êle infere cinco possíveis ordens políticas futuras ${ }^{37}$ a partír de um fenômeno macro, tomado como cruciāl em relação aos hiatos nas estruturas sociais.

Essa abordagem possui, em relação aos estudos de área, um nivel de generalidade bem mais elevado; conseqüentemente, os padrões de explicação e predição se sobrepõem. Nessa elaboração, quase todos os elementos que são oferecidos como explicação para a mudança do sistema político participam também da base para a predição. Essses elementos são, por um lado, a intensidade do comprometimento das elites nacionais com a democracia e a modernização e, por outro lado, "a quantidade de recursos da estrutura social, da tradição cultural e das qualidades e habilidades humanas" disponíveis. ${ }^{38} 0$ que explica a mudança é também o que explica o estado final. Além disso, emerge dessa elaboração um ponto teórico crucial: a conceituação do desenvolvimento político implica no estabelecimento de condições teóricas sob as quais um sistema político evoluirá em direção a um estado definido $X$. 0 que condiciona a emergência do estado $X$ dos sistemas políticos? A necessidade de uma ligação teórica entre um estado de coisas, que pode em princípio ser realizado em qualquer parte, e certas condições iniciais dadas, desloca a investigação para além do nível de conexões temporais de uma única seqüência de eventos. ${ }^{39}$

Esse nivel mais elevado de generalidade foi obtido, no en-

\footnotetext{
25 Tais tendencias foram inferidas não apenas a partir dos fenómenos básicos anteriormente citados, mas, também, do trouxeram para discussão.

* Ver a seguinte citaçăo: "Este trabalho năo faz prediçóes: é apenas um ensaio sobre o sentido e significado potencial de tendencias existentes." Brsezinski, Zbigniew. The politics of under-development. Zbigniew. The politics of under-deve
World Politics, (1): 55, out. 1956.

7 Shills, Edward. Political development in the New States. passim. A argumentaçáo de Shills náo precisa ser aqui transcrita. Deve ser dito, no entanto, que o macro hiato se encontra profundamente analisado, tanto que em vez de falar em térmos de fenómenos-macro, levando a conseqüencias diversas, é preferivel falar em têrmos de condiçóes

iniciais $a, b, c, \ldots n$.

- Shills, Edward. op. cit. p. 12.

"Delineamos, nas páginas seguintes, consequéncia do intercurso entre buscado a necessidade obstinada". Shilis. op. cit. p. 50 .
} 
tanto, ao custo de deixar sem resposta muitas questões: como é possivel que as mesmas condições iniciais conduzam a cinco estados diferentes de coisas? ${ }^{40} \mathrm{~A}$ resposta de que tais diferenças dependem do comprometimento das elites é insuficiente porque se estabeleceu, como pressuposto, que 0 resultado do comportamento da elite, e mesmo o aumento ou redução de seus comprometimentos, são refratados pela necessidade intratável das condições iniciais. Outro problema consiste em saber até que ponto o estado de coisas em $t_{2}$ se diferencia principalmente em função dos arranjos institucionais, da composição do poder, do processo de modernização, ou em relação aos recursos disponíveis para a elite política. Deve-se, portanto, perguntar qual a escala de prioridades, entre tais dimensões, que permite 0 estabelecimento de distinções entre as prováveis conseqüência. $E$, finalmente, é possivel reunir as condições iniciais sob conceitos teóricos ao invés de descrições contingentes? Exemplos disto seriam os conceitos de "capacidade para persuadir" e "capacidade para coagir" de que trata Von Vorys.

A medida que tais questões são colocadas, a direção da elaboração futura torna-se aparente. A fim de explicar e predizer o desenvolvimento político, algumas condições gerais iniciais têm que ser definidas; deve haver um intercurso entre tais condições e outras variáveis, e o movimento a partir dal gerado tem que ser previsto. Os estudos de área apontaram para algumas relações ainda imprecisas entre recursos políticos, orientação da elite e estrutura social, embora lidassem com elas ao nivel mais elementar de complexidade.

Os estudos de prognóstico também apontaram nessa direção e embora possuam um nível mais elevado de generalidade, permanecem ainda muito próximos às descrições contingentes. A vantagem oferecida pelos estudos de prognóstico consiste na ênfase da ligação ex-ante entre 0 estado final e as condições iniciais. Em que nível êsse estado final deve ser compreendido, entretanto, bem como o status teórico das condições iniciais constituem questões abordadas pela última categoria de estudos sôbre desenvolvimento político que será discutida a seguir.

Como conseqüência dos vários estudos já realizados - estudos de área e estudos de prognósticos - existe um tipo de elaboração que se situa no limiar de maior grau de complexidade e generalidade, acompanhado do mais alto rigor lógico. Esses estudos têm abordado

incógnitas diferentes da equação do desenvolvimento político, e serão aqui apresentados de acôrdo com sua ênfase principal. E desnecessário salientar que alguns entre êles tratam de mais de um problema crucial, o que será devidamente salientado.

Uma elaboração mista é apresentada em Os estágios do desenvolvimento político. A obra de Organski situa-se em três niveis diferentes de generalidade. 0 primeiro tem caráter macro-histórico, tratando da formação das nações, "desde seu início no século XVI (...) e daí em direção ao futuro até o ponto em que se supõe seu eventual desaparecimento." 410 pressuposto é o que existiu um período do macro-histórico no período imediatamente anterior, e que existirá um outro período macro-histórico posteriormente ao período nacional em estudo. 0 problema teórico consiste em explicar como a humanidade evoluiu de um período pré-nacional ao período nacional, bem como a viabilidade do período pós-nacional. Quais foram as condições que produziram a forma nacional de organização política? Quais são as condições que conduzirão a humanidade ao estágio macro-histórico pós-nacional, e como será êle?
O segundo nível de generalidade trata da seqüência do desenvolvimento dentro de limites traçados pela existência do estado nacional. E nesse nível que 0 desenvolvimento político pode ser definido como "eficiência governamental crescente na utilização dos recursos humanos e materiais da nação, tendo em vista objetivos nacionais. (...) A função primária do govêrno nacional também se modifica à medida que a nação evolui de um estágio para outro, e a cada estágio o govêrno nacional, se fôr qualificado como 'desenvolvido', deve preencher a nova função bem como consolidar as vantagens auferidas no passado." 42 O problema teórico, aqui, é explicar como cada um dêsses estágios está teòricamente, e não apenas temporalmente, ligado ao seu antecedente. Deve ser observado que, de acôrdo com essa perspectiva, a explicação teórica da emergência do primeiro estágio nacional deve ser entendida como o conjunto de condições empíricas sob as quais foi feita a transição do período macro-histórico pré-nacional ao período macrohistórico nacional. De forma análoga, a explicação adequada para a exaustão do último estágio nacional define também as condições empíricas sob as quais emerge o momento inicial do estágio pós-nacional. Finalmente, 0 terceiro nível aborda aparato institucional capaz de conduzir a cada um dêsses estágios nacionais. Uma vez que Organski pressupõe que não há relação biunivoca entre os estágios de desenvolvimento político e regimes políticos, torna-se necessário discutir as condições sob as quais surgem os diferentes aparatos governa-

\footnotetext{
10 Em artigo recente, Huntington discute precisamente o caso oposto, isto é, como diferentes condiçóes iniciais levam ao mesmo resultado. Ver Political modernization: America versus Europe. World Politics, 18 (3): abr. 1966. i1 Organski, A. F. K. The stages of political development. 1965. p. 3. - Organskl, A. F. K. op. cit., p. 7.
} 
mentais e, ainda, se existe alguma relação entre o tipo prévio de govêrno e o tipo de regime que o sucederá como estágio de construção da nação.

No que se refere às respostas no primeiro nivel, Organski não é muito claro. A emergência da forma nacional de organização política é atribuída à busca do poder, quer pelos monarcas absolutistas, quer pelas potências colonizadoras. Isto viria também explicar a estrutura de poder ou o aparato institucional do primeiro estágio, que consiste na política de unificação primitiva. ${ }^{43}$ De um ponto de vista cronológico, essa explicação seria razoável no que se refere à transição do período macro-histórico pré-nacional. Entretanto, como essa passagem de sua elaboração deve ser teòricamente vinculada à explicação da emergência do primeiro estágio de construção nacional, torna-se difícil aceitar que nas novas nações contemporâneas êsse estágio de unificação primitiva seja devido a qualquer uma das razões apresentadas. Não existem nem monarcas absolutos nem possibilidades colonialistas, dentro das novas nações independentes, para explicar sua evolução através dêsse primeiro estágio. A idéia da difusão de uma cultura mundial, de Pye, poderia ser uma explicação mais adequada. No que se refere à transição para o período pós-nacional, a questão é também deixada em aberto. o último estágio conhecido do macroperíodo de construção nacional pode perfeitamente provocar o fim da própria forma nacional, porém nada conclusivo é dito a êsse respeito. ${ }^{44}$

Observe-se que o padrão de explicação é bem mais frouxo nesse nivel; e novamente a explicação se separa da predição na medida em que a explicação é uma reconstrução ex post facto do que històricamente ocorreu, conforme 0 critério de relevância do autor, a saber: a construção do estado nacional.
O segundo nivel de elaboração deve explicar a seqüência do desenvolvimento, isto é, da unificação primitiva à política de industrialização, daí à política de bem-estar social e, finalmente, à política da abundância. Já foi salientado

que o primeiro estágio surge da busca pelo poder, o que consiste em uma explicação do tipo individualista. A transição do primeiro ao segundo estágio, e daí para o terceiro, depende do preenchimento dos objetivos de cada estágio que, por sua vez, é função da luta pelos recursos escassos. Quando o terceiro estágio é atingido, não é mais necessária a luta econômica; e o fator crucial, responsável pelo quarto estágio - a política de abundância - são as modificações tecnológicas na produção econômica - enfim, a automação. Três fatôres fundamentais são introduzidos na explicação requerida nesse nível: motivações individuais, luta política, e mudanças tecnológicas: cada uma delas é introduzida de acôrdo com as conveniências da elaboração. Enquanto padrão explicativo, isso é inconsistente e não apenas insatisfatório. 0 poder preditivo da elaboração é absoluto, sòmente porque depende de definição. De fato, se uma nação entrou ou não em um determinado estágio dependerá apenas daquilo que fôr considerado como melhor índice da condição de industrialização ou da condição de bem-estar, ou da condição de abundância. Uma vez que o problema se reduz a definições, a seqüência dos estágios será determinada exclusivamente por tais definições, não havendo pois como falsificá-las. As predições, nesse caso, não possuem relevância epistemológica.

Quanto ao terceiro nivel de elaboração, hipóteses mais específicas são apresentadas. Desdobremos as questões e tratemos separadamente de (a) formas de govêrno em cada estágio e (b) passagem eventual de uma forma a outra.
Não há elaboração adicional quanto a formas de govêrno que possam desempenhar as funções do primeiro estágio, além de simples enumeração, a saber: política dinástica, política colonial, política dos novos países independentes, e política das antigas nações econômicamente atrasadas. ${ }^{45}$ No segundo estágio pode-se observar a emergência de três diferentes tipos de regime: burguês, sincrático e stalinista. 0 tratamento do modêlo burguês apenas descreve o que a burguesia fêz após assumir o poder, sem oferecer qualquer explicação para o surgimento do modêlo. ${ }^{46}$

0 modêlo sincrático é apresentado com uma explicação: meados do processo de industrialização + poderosa aristocracia latifundiária + elite industrial tão forte quanto a elite agrária + percepção por parte dos agriculturalistas de que estão perdendo o poder + desejo de compromisso por parte dos industriais = surgimento do modêlo sincrático. ${ }^{47}$ O modêlo stalinista, por outro lado, possui duas explicações. A primeira apresenta a seguinte fórmula: baixo nível de modernização econômica + aristocracia agrária fortemente entrincheirada + desejo das novas elites de rápida industrialização + colapso, na guerra, do antigo

sistema $=$ modêlo stalinista. ${ }^{48}$ Noutro ponto, entretanto, 0 modêlo stalinista é simples função da velocidade de mudança social e econômica desejada pelas elites modernizadoras. ${ }^{49}$

Além dessas hipóteses, a elaboração do estágio dois oferece duas hipótese adicionais. Uma trata da disponibilidade dos industrialistas de barganharem no modêlo sincrático:

\footnotetext{
- Ibid. p. 7ff

4 Ibid. p. 187.

4 Ibid. p. 21.

4 Ibid. p. 56-93.

\& Ibid. p. 217.

4 - Ibid. p. 215

$\triangle$ Ibid. p. 218.
} 
expansão industrial seguida de retratação econômica + ameaça à elite, vinda de

baixo, = disposição de barga-

nhar. ${ }^{50}$ A outra trata de um

modêlo ditatorial não

especificado: baixa industriali-

zaçāo + alta politização đas

massas $=$ modêlo ditatorial. ${ }^{51}$

O terceiro estágio pode ser realizado por três modelos - a democracia de massa, o nazismo e o comunismo - tipo Khruschev. A democracia tem origem nos modelos sincráticos e burguês, ao passo que o modêlo comunista tipo Khruschev tem origem no modêlo stalinista. O modêlo nazista, por outro lado, é visto como um possível desvio da democracia de massa, sob as seguintes condições: decadência do aparato estatal + alto nível de desemprêgo + inflação galopante. ${ }^{52} \mathrm{O}$ modêlo nazista, portanto, não é autônomo, mas sim um contraponto patológico das democracias de massa.

\section{Essas últimas explorações} possuem um poder explicativo e preditivo de alto nível, de um ponto de vista estritamente lógico: sua maior fraqueza consiste nas possibilidades tecnológicas de operacionalização e mensuração. Uma vez que se está prevenido do que deve ser operacionalizado e que tipo de medida deve ser buscada, tais devem ser os passos estratégicos a serem tomados. Já que as últimas elaborações de Organski coincidem com outra categoria de estudos sôbre desenvolvimento político, elas serão discutidas mais adiante.

O conjunto seguinte de estudos será grupado sob o título de teorias formais de mudança política. Nesse contexto, são consideradas formais porque especificam as condições sob as quais o sistema político tende a mudar, sem se comprometerem quer com a especificação do estado antecedente $X$ ' quer com 0 produto resultante X". A forma geral de predições e/ou explicação da mudança em tais estudos consiste na apresentação de duas dimensões dos sistemas políticos, definidas como fundamentais, e na indicação de que a mudança política ocorrerá sempre que se estabelecer um certo intercurso entre as duas dimensões. Citamos, a seguir, alguns exemplos dessa elaboração:

a) coerção $X$ informação; 53 b) capacidade de contrôle $\times$ demandas por contrôle, ${ }^{54}$ c) capacidade de contrôle $X$ igualdade de participação; ${ }^{55}$

d) capacidade de contrôle $X$ igualdade. ${ }^{56}$

Nesse nível, a convergência das elaborações é bastante alta. As dimensões do lado esquerdo da relação apontam tôdas para a mesma direção. Do lado direito a única discrepância é a variável "informação", de Apter. Riggs e Coleman referem-se à mesma dimensão (igualdade), e a dimensão de Von Vorys (b) inclui não apenas $a^{-}$ demanda de participação, no sentido político, mas também demandas por mercadorias e semelhantes. Elas diferem, no entanto, quanto ao tipo de intercurso que entre elas se estabelece. Coleman não se refere a nenhuma forma precisa da relação ou à sua dinâmica, talvez porque isso será discutido no volume final da série de Princeton. Apter sugere que a relação entre informação e coerção dependerá das condições iniciais do sistema político, isto é, na estrutura de autoridade e dos valôres prevalescentes. ${ }^{57}$ Riggs e Von Vorys, finalmente, chegam à mesma conclusão embora, aparentemente, avaliem-na de forma diferente. Para Von Vorys a mudança no sistema político ocorre quando a demanda por contrôle atinge, e em seguida ultrapassa, a capacidade de contrôle, o que seria uma situação indesejável. ${ }^{88}$ Para Riggs é exatamente o equilíbrio entre contrôle e igualdade que provoca a mudança do sistema político em direçẫo a um nivel mais elevado de desenvolvimento. ${ }^{50} \mathrm{Se}$ fôsse possível medir o que ambos entendem por tais capacidades, obteríamos uma situação quase experimental. Enquanto Riggs prevê como resultado da mudança mais ordem e mais mercadorias para serem distribuídas, Von Vorys prevê exatamente o contrário, isto é, o caos.

A partir da discussão precedente evidencia-se que o nível de clareza e precisã̃o lógica de tais elaborações é relativamente alto. Isso é ainda verdade no que se refere à generalidade das proposições comparadas mesmo com os mais rigorosos estudos de área. A implicação lógica consiste no seguinte: se $X$ (equilíbrio entre capacidade de contrôle e demanda por contrôle, ou igualdade), então $Y$ (caos) ou $Z$ (desenvolvimento). Não há restrição temporal ou espacial alguma em

50 Ibid. p. 217.
6 Ibid. p. 219.
62 Ibid. p. 171.
63 Apter, David. The politics of

modernization. 1965. principalmente modernization. 1965. principalmente o além daquela que será mencionada mais adiante. Ver nota 57 .

a Von Vorys, Karl. Use and misuse of development theory. In: op. cit. Charlesworth (ed.)

is Riggs, Fred. op. cit., loc. cit.

bo Coleman, James S. Education and political development. Introduction to James S. Coleman (ed.).

67 Apter, D. op. cit. p. 409ff. Parece que a inclusăo da elaboração de Apter no conjunto de teorias formais sôbre a mudança politica não é justificada. Entretanto, estamo-nos baseando

principalmente em sua sugestăo no

Prefácio (ediçăo Phoenix de 1967) na qual as dimensões informaçăo e coerçăo assumem papel central. Já que Apter diz que sua opiniảo modificou-se desde a primeira edição original, e porque promete um nôvo livro em que apresenteria a nova formulaçao, preferimos desconsiderar as ligaçōes estabelecidas no livro e tomar apenas os conceitos expressamente enfatizados no Prefácio.

68 Von Vorys, Kail. Use and misuse of development theory. op cit., p. 356 . apenas discutindo a viabilidade dos
sistemas politicos, e que essas săo as

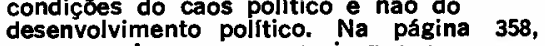
por exemplo, parece sugerir que o por exemplo, parece sugerir que o permanente da capacidade de controlar em relaça à demanda por contrôle. Nossa opiniăo, ao longo deste trabalho, pode bem năo estar de acórdo com a visão de Von Vorys sobre o assunto.

- Riggs, Fud. op. cit., p. $341 f$. 
tal proposição, o que lhe assegura um status teórico

elevado. A única limitação ao seu poder preditivo consiste no fato de não estar previsto o estágio seguinte (ou estado) do sistema político. Predizem a mudança em direção a que? Esta indagação é de fundamental importância na teoria do desenvolvimento político. A preocupação com predições relativas ao estágio seguinte pode ser encontrada nos dois tipos de elaboração discutidos a seguir.

Em contraste com o conjunto de estudos que acabamos de ver e que chamamos de teorias formais sôbre a mudança política, existe um tipo de elaboração que pode ser chamado de teorias substantivas sôbre a mudança política. Aqui a ênfase está no movimento do sistema político conducente a um estado especificado $X$. Um exemplo seria o artigo de LaPalombara, no volume Burocracia e desenvolvimento político. ${ }^{60}$ LaPalombara preocupa-se não só com a definição do estado futuro de desenvolvimento político, mas também com as condiçōes sob as quais o estado democrático de desenvolvimento político pode ser atingido. Tais condições teriam a ver com (a) acentuada

falta de ênfase nos objetivos econômicos, (b) limitações do papel do setor público no desenvolvimento econômico e fortalecimento do setor privado, e (c) contrôle das demandas feitas ao sistema político. ${ }^{61}$

A elaboração de LaPalombara aproxima-se bastante da de Huntington - Desenvolvimento e decadência política - porém, enquanto êste fala de "institucionalização", LaPalombara fala em "democracia". Como já foi acentuado, êsse tipo de elaboração possui um padrão de predição a um nível intermediário de generalidade. 0 objetivo de predição é universal, mas o universo ao qual se aplica é limitado. No nosso entender, êsse é um nível legítimo de elaboração científica, porém como freqüentemente assume
- como em LaPalombara uma forma prescritiva de apresentação, e porque há uma certa controvérsia relativa ao fato de que qualquer tipo de proposição prescritiva afasta-se do campo científico, referir-nos--emos ràpidamente a êsse aspecto.

Freqüentemente, a posição de que proposições científicas e proposições prescritivas são diferentes baseia-se no pressuposto de que são respostas diferentes a problemas diferentes e que, provàvelmente, possuem estrutura lógica diferente. A seguinte citação deixa essa postura bastante clara:

"Não estou sugerindo que as indagações relativas à ausência de democracia, suas causas e as perspectivas de democracia não sejam perguntas relevantes para o cientista político preocupado com tais países (os novos países). Não digo sequer que a prescrição política não deva ser sua atividade; sugiro, no entanto, que êstes são papéis distintos que devem ser mantidos separados conscientemente, pois sua confusão coloca em perigo o desempenho de qualquer um dêles. O cientista político como estudioso não evoluído pergunta uma ordem de questões diferentes daquela que perguntaria como assessor político. Ele está antes de mais nada preocupado com um conjunto de relações que possam ser inferidas de dados observáveis, isto é, quais são suas conexões causais, na medida em que podem ser discernidas, e suas conseqüências, na medida em que podem ser previstas, nesta ordem." 62

Nosso ponto de vista é o de que, desde que verificadas, as proposições prescritas são lògicamente equivalentes às

proposiçōes preditivas com base em condições de suficiência. Tomemos, por exemplo, a seguinte proposição prescritiva: se se deseja $X$, então deve-se fazer (ou obter) a, b, c. A proposição é válida se a seguinte proposição é também válida: se a, b, c, então X. A última é uma proposição científica, chamada puramente científica, enquanto a primeira expressa a forma geral de declaração prescritiva. Essa equivalência constitui o cerne da racionalidade de qualquer atividade científica, porque na sua ausência seria impossível demonstrar experimentalmente a legitimidade de qualquer proposição científica. 0 suporte lógico do experimento como teste de validade de uma proposição científica consiste, nada mais nada menos, que nesta ou similares equivalências. 0 problema com as declarações prescritivas em problemas sociais não reside na equivalência em si, mas no fato de que muito freqüentemente a declaração preditiva (se a, b, c, então $\mathbf{X}$ ), que deveria apoiar a declaração prescritiva, é falsa.

Não há uma ordem diferente de questões a serem articuladas, em têrmos preditivos ou prescritivos, nem seu padrão Iógico é completamente diferente. No que se refere à teoria de desenvolvimento político, o interêsse prescritivo é equivalente ao interêsse que teòricamente aparece como "teoria substantiva da mudança política"; cujo problema principal, como em qualquer outra atividade científica, é produzir proposições verdadeiras.

Deve ainda ser dito, no entanto, que tal tipo de elaboração está ainda em estágio bastante atrasado, quando comparado às teorias formais da mudança. Nesse último encontramos maior consenso, não apenas em têrmos das dimensões que devem ser consideradas como relevantes, mas também quanto aos conceitos teóricos principais, aos quais já se atribuiu um

\footnotetext{
- LaPalombara, Joseph. Bureaucracy and political development: notes, queries and dilemmas". In: op. cit. Lápalombara.

or LaPalombara, Joseph. Bureaucracy .. p. 56-68.

Wilner, Ann Ruth, The underdeveloped study of political development. World Politics, 16 (3): 473, abr. 1964.
} 
significado aproximadamente igual. $O$ ponto estratégico é como encontrar medidas apropriadas para as dimensões e condições adequadas de prova. Nas teorias substantivas de mudança política a situação é bem rudimentar. Não há consenso quanto a conceitos fundamentais tais como democracia, autoritarismo, ditadura e não há consenso no que se refere às condições que devem ser consideradas para explicar a mudança substantiva. Conseqüentemente, 0 poder explicativo e preditivo é atualmente baixo, embora sua temática seja de nível significativo de generalidade. ${ }^{63}$

Finalmente, abordaremos a elaboração mais complicada sôbre desenvolvimento político: a elaboração de Almond, sòzinho ou em co-autoria. Sua atividade teórica, apontando para várias direções ao mesmo tempo, chama a atenção para vários aspectos frutíferos $\mathrm{e}$, algumas vêzes, tenta, prematuramente, sintetizar e colocar dentro do mesmo esquema as muitas pistas descobertas. $\mathrm{Na}$ discussão seguinte consideramos estar o leitor familiarizado com seu pensamento básico a fim de não estendermos em demasiado a discussão.

\section{Em Abordagem desenvolvimen- tista aos sistemas políticos é} sugerido que 0 desenvolvimento dos sistemas políticos pode ser conceituado de acôrdo com o que Almond chama "lógica das capabilidades". 64 Isso indica uma linha de raciocínio na qual as relações entre as várias capabilidades, e a forma pela qual os conjuntos de capabilidades variam de acôrdo com variações em cada uma delas, assumem grande importância. Nessa linha de raciocínio, a discussão sôbre as formas pelas quais os conjuntos se correlacionam aos arranjos institucionais (ou processos de convenção) é adiada até que compreensão clara da lógica das capabilidades seja atingida. ${ }^{\text {es }}$ Essa posição é novamente enfatizada numa série de conferên- cias posteriores em que recomenda uma "polimetria" (mensuração do comportamento do sistema), baseado apenas na lógica das capabilidades. ${ }^{66}$

Por outro lado, no mesmo artigo (abordagem desenvolvimentista), êle argumenta que "a teoria da mudança política lida com aquelas transações, entre o sistema político e seu ambiente, que ocasionem mudanças no desempenho do sistema político, ou capabilidades, que, por outro lado, estejam associadas com mudanças no desempenho das funções sistêmicas de adaptação e de conversão. ${ }^{67}$ Essa conexão entre capabilidades e outras funções do sistema político, como forma de conceituação do desenvolvimento político, será novamente proposta em seu último livro. ${ }^{68}$ Tentaremos, no parágrafo seguinte, organizar os vários tipos de dimensões incluídos no livro, bem como as linhas de conceitualização propostas. Parte dêsse trabalho será inferida e, portanto, é possível que surjam dúvidas sôbre a apresentação da lógica básica da elaboração original.

Parece que a elaboração lida com três tipos de dimensões. Vamos chamá-las de: institucionais $(A)$ - processos de conversão + socialização política + recrutamento político; atitudinais $(B)$ - cultura política; ${ }^{69}$ e de desempenho (C) capabilidades. O A é predicado a partir da organizaçãa societal, - B, a partir da população, e C, é predicado a partir do sistema político. A confiar nas sugestões dadas a partir da página 205, seria possível dizer que $\mathbf{A}$ é função do tempo, ou desempenho, ou do meio ambiente; B é também função do tempo, ou desempenho, ou meio ambiente; e C é função dos recursos e apoios e aparato governamental e objetivos das elites. Da página 300 a 322, entretanto, A, B, e C são apresentados como se devessem existir em equilíbrio ou congruência; porém, novamente, à página 323 , as capabilidades são função da diferenciação estrutural e secularização cultural, e nada é dito sôbre a autonomia estrutural. Finalmente, na seção "O porquê do desenvolvimento", os estágios do desenvolvimento político são vistos como função da crise da construção da Nação e da construção do Estado, da crise de participação e da crise de distribuição.

Nessa elaboração múltipla podemos assinalar três tipos diferentes de problemas relacionados ao desenvolvimento político. 0 primeiro tem a ver com a lógica das capabilidades, onde o objetivo é definir o que Almond chama de "perfil de capabilidades". Em seus livros e artigos existe uma série de declarações quanto à forma de estudar tais perfis e sua dinâmica. Por exemplo, um acréscimo na capacidade extrativa implica em decréscimo na capacidade distributiva; um acréscimo na capacidade regulatória implica em redução na capacidade responsiva. ${ }^{70}$ Tais sugestões, entretanto, parecem ter como parâmetro o fator

a Tais são os problemas tratados na elaboração de organski quanto a tipos de regimes. As elaboraçōes bastante semelhantes de Kautsky, em The politics of the underdeveloped areas tratam, também, de tais dificuldades.

* Almond, Gabriel. A developmental approach to political systems. World Polites, 17: p. 199 jan. 1965.

* Ver Almond, G. op. cit. p. 197. * Almond, Gabriel. Perspectives on political development. Benedict Lectures on political philosophy. Boston University, mar. 1968, mimeo. 18, 19, 20, passim. Esta proposiçăo não e absolutamente verdadeira. A Iógica das capacidades, sugerida nas condiçóes iniciais dos sistemas políticos, e ainda os objetivos das elites. Porém, é ainda verdadeiro que năo se acentua relação alguma com os arranjos institucionais.

an Almod, G. op. cit. p. 191.

* Almond, Gabriel. \& Powell Jr. G. Bingham, Comparative politics a developmental approach. Ver, por exemplo, p. 300-322.

* E verdade que em civic culture, Almond \& Verba distinguem a cultura política dos puros atributos atitudinais ou variáveis. Neste contexto, entretanto, a classificação diferenciar uma dimensão da outra.

v Estamos usando indiferentemente os têrmos capabilidade a capacidade para indicar a mesma noçăo, isto é, a possibilidade de implementar decisőes tomadas pelo estado, ou govêrno, ou sistema político. 
tempo. Mesmo assim, muitas das elaborações mencionadas, bem como evidências empíricas apontam para o fato de que não é o aumento, digamos, na capacidade extrativa per se, que importa, mas principalmente a taxa de aumento através do tempo. Não é a pressão pelo desenvolvimento econômico que leva ao aumento das capacidades extrativas e regulatórias ao custo da redução das capacidades responsivas $\mathrm{e}$ distributivas, mas sim a pressão pelo rápido desenvolvimento econômico. A lógica das capabilidades, assim, prepara o caminho para a absorção do tempo, não como um parâmetro da análise, mas como um dos têrmos da equação do desenvolvimento político. $E$ isso, provàvelmente, seria 0 passo mais significativo em direção ao ideal do conhecimento científico, na medida em que a teoria do desenvolvimento político é dinâmica e, forçosamente, teria que proceder à redução do fator tempo a uma categoria controlada pela teoria. ${ }^{71}$ Além disso, 0 estudo dos perfis de capabilidades pode propiciar a fonte para explicar e situar, dentro do mesmo esquema de explicação, fenômenos pràticamente reconhecidos como universais nos estudos de área, isto é, a difração imposta pela sociedade sôbre a vontade e comportamento das elites, bem como o impacto diferencial do comportamento da elite sôbre a sociedade. $O$ estudo dos perfis de capabilidade, portanto, parece ser a linha mais promissora de elaboração, tendo em vista o ideal de uma teoria dinâmica do desenvolvimento político.

A segunda linha de raciocínio trata das estruturas. Estamos lidando com dimensões que são, em sua maioria, atributos do sistema político. Um sistema político tem ou não estruturas diferenciadas para a articulação política e, da mesma forma, possui ou não estruturas diferenciadas para a agregação política. $O$ que se entende por desenvolvimento político consiste, aqui, em tomar momentos diferentes no tempo, nos quais os sistemas políticos demonstram possui atributo antes inexistente. 0 contínuo de diferenciação estrutural só é um contínuo do ponto e vista formal, porque, de fato, carece de sentido dizer que o sistema político está no estado 1,2 e 3 no processo de diferenciação de uma instituição para a articulação de demandas, como por exemplo, um sindicato. ${ }^{72} \mathrm{O}$ que está implícito nesta abordagem não são pròpriamente problemas de desenvolvimento mas aquilo que na economia é chamado de estática comparada, isto é, a comparação estrutural do sistema político em dois momentos diferentes no tempo, sem que seja possivel dizer o que é responsável pelas diferenças encontradas. Tal linha de estudos pode produzir, é claro, muitos resultados significativos, porém não trata das questões mais importantes do desenvolvimento político.

0 terceiro tipo de problemas a ser considerado consiste nas relações entre perfis de capacidades e arranjos institucionais. Em outras palavras, existe uma relação de tipo biunívoco entre perfis de capacidades e os arranjos institucionais? Ou é possível que mais de um tipo de arranjo institucional apresente a mesma habilidade para desempenhar um perfil determinado de capacidades? Almond apresenta uma série de indicações ao longo do raciocínio, e êsse campo parece ser extremamente rico, desde que o trabalho preliminar de estabelecimento dos perfis tenha sido feito. Nossa dúvida, no entanto, consiste em saber se esta linha de raciocínio pertence, de fato, ao campo do desenvolvimento político. Não temos uma posição definida nesse aspecto, porém parece que êsse tipo de problema requer uma análise diferente da abordagem em têrmos de desen- volvimento. Por outro lado, parece claro que se o perfil das capabilidades no tempo $t_{2}$ fôr derivado do arranjo institucional no tempo $t_{1}$, não haverá lugar para o que foi dito antes sôbre o comportamento da elite, dos recursos e do apoio disponivel, entre outros aspectos. Um nôvo tipo de mecanicismo institucional teria sido introduzido na teoria. Mas êsse campo, seguramente, requer análises mais profundas. $\mathrm{Na}$ elaboração de Almond, portanto, podemos encontrar um padrão de conceituação que pressupõe tanto a explicação quanto a predição, possuindo poder potencial para incluir tôdas as variáveis relevantes descobertas em niveis diferentes de elaboração. Referimo-nos à lógica das capabilidades que, aparentemente, parece ser capaz de considerar também a variável mais difícil na teoria social - o fator tempo. 0 risco dessa elaboração é tentar uma vinculação prematura entre os perfis de capabilidades e os arranjos institucionais, e, portanto, desviando o esfôrço para formas de investigação cujos fundamentos lógicos são, pelo menos, questionáveis.

$\pi$ Karl von Vorys tem um dos poucos estudos que tentam relacionar variáveis teóriamente importantes com o fator tempo. Entretanto, em seu esfôrço o fator tempo desempenha ainda muito mais o papel de parámetro que um dos tèrmos da equaçăo.

7. No sentido histórico, naturalmente, 6 possivel ver como tais instituiçסes surgiram e se desenvolveram. Mas, ésse processo abstraido da experiência macro-hist6rica de tôda a humanidade năo pode ser apenas atribuido a processos operando dentro de um sistema político singular, a menos que estejamos prontos para nos perdermos entre milhares de detalhes que formam o processo histórico singular de cada instituição, dentro de cada nação. Para o objetivo da conceitualização cientifica, a diferenciação astrutural deve ser entendida em termos de atributcs adquiridos através do tempo pelo sistema político. Quanto a "autonomia" outra dimensão crucial neste nivel de análise - deve ser entendida em têrmos de "nenhuma", "semi" e "completa".

Porém, dificilmente conseguimos ver como atribuir significado empírico a essa possibilidade térica, sem cair nos problemas já mencionados por Robert $T$. Holt e John E. Turner em The political

basis of economic development - an exploration in Comparative political analysis. cap. 1. 
Essa era a última elaboração a a ser coberta no presente artigo. Buscando padrões básicos de explicação e predição, tivemos que reduzir dràsticamente os estudos analisados, a fim de tornar explícitas apenas aquelas estruturas lógicas mais relevantes para a construção teórica de uma teoria de desenvolvimento político. Muitos padrões de explicação e predição estão, de fato, implícitos em tais elaborações, em níveis distintos de generalidade e complexidade. Alguns dêles se encontram bastante distantes do ideal científico, mas certamente todos contribuem para a construção de uma teoria do desenvolvimento político. 0 problema crucial não consiste em saber se êles possuem ou não as propriedades do conhecimento científico formalizado, mas sim em como desenvolver, em cada nível de complexidade, o tipo de compreensão que envolvem, como passo necessário em direção à construção teórica. A preocupação básica dêste artigo consistiu em determinar padrões modais de explicação e predição, e discutir em cada padrão aquilo que parece ser a forma de aprimorar sua contribuição para o produto final, a saber: uma teoria dinâmica do desenvolvimento político. Foi, assim, determinado que os padrões modais podem ser grupados de acôrdo com o seguinte tipo de elaboração: estudos sôbre o estado do desenvolvimento político; estudos de área; estudos de prognósticos; estudos mistos (Organski); teorias formais da mudança política; teorias substantivas da mudança política; e análise das capabilidades. Esperamos que, de acôrdo com a proposta de estratégia inicialmente sugerida, algumas indicações a respeito de como fortalecê-los lògicamente tenham surgido ao longo da exploração.

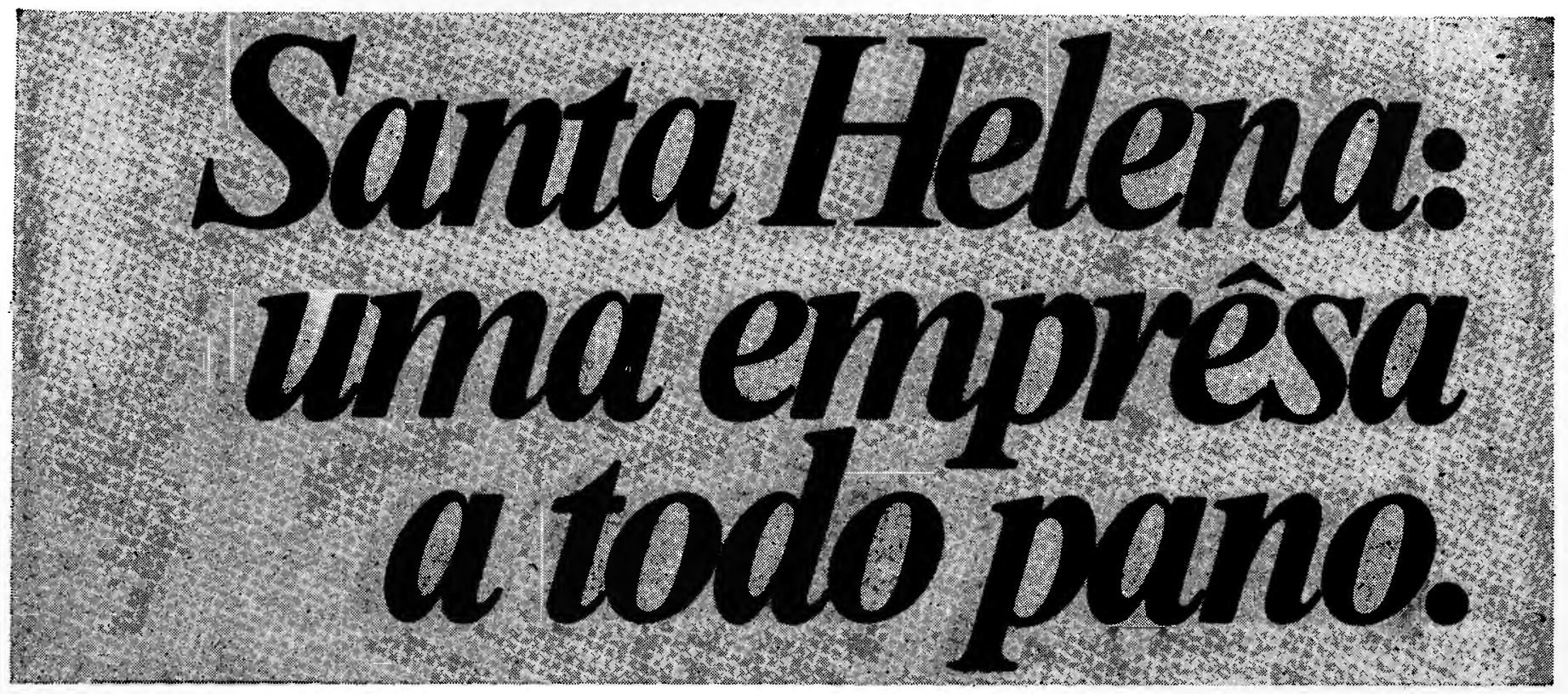

Santa Helena começou a fabricar tecidos em 1909. E ràpidamente se firmou como criadora de tecidos de alta classe. De grande qualidade. Atualmente, ela está mais viva do que nunca. Produzindo a todo pano, tecidos que fazem a moda. Santa Helena - uma emprêsa de bom gôsto.

S.A. FABRICA DE TECIDOS st SantaHelena Petrópolis - R.J. 